\title{
Pretreatment neutrophil to lymphocyte ratio in determining the prognosis of head and neck cancer: a meta-analysis
}

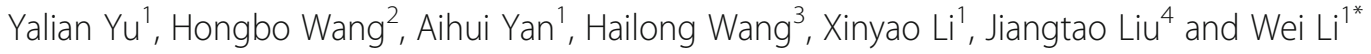

\begin{abstract}
Background: Recent studies have reported a relationship between prognosis and neutrophil-to-lymphocyte ratio (NLR) in patients with head and neck cancer (HNC). As the results are still controversial, we conducted a meta-analysis of pretreatment NLR in peripheral blood and prognosis in HNC patients.
\end{abstract}

Methods: We retrieved articles from PubMed, Medline, Cochrane Library, Embase and Web of Science. A comparative analysis was conducted for the effect of pretreatment NLR in peripheral blood on overall survival (OS), progression-free survival, disease-free survival (DFS), disease-specific survival, metastasis-free survival, and recurrence-free survival of HNC patients. The analysis applied the criteria for systematic reviews described in the Cochrane Handbook and was conducted using hazard ratios (HRs) to estimate effect size, and calculated by Stata/SE version 13.0.

Results: The meta-analysis included eligible cohort studies (5475 cases). The OS data indicated increased mortality risk in HNC patients with a high NLR ( $H R=1.84,95 \%$ confidence interval $(C l): 1.53-2.23 ; P<0.001$; heterogeneity, $I^{2}=37.2 \%, P=0.074$ ). Analysis of subgroups stratified by NLR cutoff values revealed increased mortality risk and significantly shorter DFS in patients with high NLR compared to those with low NLR $(H R=2.18,95 \%$ Cl: 1.46-3.24; $P<0.001$ ). Patients with high NLR had a higher probability of tumor recurrence after treatment than those with low NLR (HR $=1.63,95 \% \mathrm{Cl}: 1.09-2.45 ; P=0.017$; heterogeneity, $\left.P^{2}=68.7 \% ; P=0.022\right)$. The probability of distant metastasis following treatment was greater in patients with high compared with low NLR (HR=1.92, 95\% Cl: 1.36-2.72; $P<0.001$; heterogeneity, $P^{2}=0.0 \% ; P=0.614$ ). Funnel plots of the meta-analysis results were stable, as shown by sensitivity analysis. No publication bias was detected by the Egger test $(P=0.135)$.

Conclusions: HNC patients with elevated pretreatment NLR in peripheral blood have poor prognosis and are prone to local invasion and distant metastasis. NLR values are easily obtained from routinely collected blood samples and could assist clinicians to determine prognosis of HNC patients.

Keywords: Head and neck cancer, Neutrophil-to-lymphocyte ratio, Prognosis, Meta-analysis

\section{Background}

Head and neck cancer (HNC) is currently the fifth most common malignancy worldwide, with $>600,000$ new cases and $>300,000$ deaths annually $[1,2]$. Despite effective surgical interventions and adjuvant therapy, the 5-year HNC survival rate of nearly $50 \%$ is still lower than that of most other cancers [3]. HNC originates in the mucosal epithelium of the oropharynx, nasopharynx, nasal and

\footnotetext{
* Correspondence: wli@mail.cmu.edu.cn

'Department of Otorhinolaryngology, the First Affiliated Hospital of China Medical University, Shenyang, Liaoning Province, People's Republic of China Full list of author information is available at the end of the article
}

paranasal sinuses, larynx and hypopharynx. Many patients are diagnosed with $\mathrm{HNC}$ at an advanced stage. Data from the United States show that more than two-thirds of HNC patients present with lymph node invasion or distant metastasis at the time of diagnosis. More than half the patients need more surgery or radiotherapy because of recurrence within 2 years of initial surgery [4]. Therefore, simple, effective and economically feasible laboratory indices that can predict increased risk of recurrence, metastasis or death in HNC patients are essential for early diagnosis and improved survival in clinical practice. 
Awareness of the presence of inflammation in the tumor microenvironment has spurred research on the relationship between inflammation and malignancy [5-10]. The progression of cancer requires interactions between tumor cells and their microenvironment, including inflammatory, immune and metabolic responses to stimuli from the surrounding tissue. The systemic inflammatory response plays a key role in tumor cell invasion by promoting microvascular regeneration, tumor metastasis, and tumor cell proliferation $[8,9,11]$. Moreover, the systemic inflammatory response facilitates the differentiation of tumor cells and suppresses activity of host immune cells [6, 12-14]. Neutrophil-to-lymphocyte ratio (NLR) is an accurate and reliable index of systemic inflammation. NLR is closely associated with prognosis of solid tumors, such as colorectal, non-small cell lung, stomach and prostate cancer [1519]. However, the association of NLR and prognosis of HNC remains controversial. For that reason, we conducted this meta-analysis of the prognostic value of NLR in HNC.

\section{Methods}

\section{Literature search strategy}

A systematic research was performed according to the Preferred Reporting Items for Systematic Reviews and Meta-Analysis (PRISMA) guidelines [20]. The research of PubMed, Embase, Cochrane Library and Web of Science identified relevant studies published in English or Chinese up to June 2016. The search strings included "head and neck cancer", "head and neck carcinoma", "head and neck neoplasms", "neutrophil-to-lymphocyte ratio", "neutrophils", "lymphocytes", and "NLR". Manual searches of reference lists in articles retrieved online were conducted to identify additional relevant studies.

\section{Literature inclusion and exclusion criteria}

Articles were included following independent searches by two of the authors (YY and XL). Disagreements were resolved by discussion or intervention by a third researcher (HW). To be included, a study had to report findings on the association between prognosis in head and neck tumors and NLR in peripheral blood before therapeutic intervention. The interventions included surgical resection, radiotherapy, chemotherapy, or combined therapy. Prognosisrelated survival data included hazard ratio (HR) with 95\% confidence intervals (CIs), or curves of overall survival (OS), progression-free survival (PFS), disease-free survival (DFS), disease-specific survival (DSS), metastasis-free survival (MFS), or recurrence-free survival (RFS). Studies were excluded using the criteria of the Cochrane Nonrandomized Studies Methods Group [21]. Duplicate reports and duplicate cases (with multiple reports of the same study, the most recent publication was selected), and case reports were excluded. We also excluded articles without available full text; articles with incomplete survival data that could not be obtained following communication with the authors; literature reviews; and conference abstracts that lacked sufficient data for meta-analysis quality assessment.

\section{Data extraction}

We extracted data indicating country or region, author, title, year of publication, journal name, postal or e-mail address, type of research, sample size, age, gender, intervention measure, tumor type, AJCC or UICC cancer stage, lesion site, duration of or lost to follow-up, HR and 95\% CI, and NLR cutoff value used to define OS, PFS and DFS. For studies that lacked complete data, the results of multivariate analysis were preferable to those of univariate analysis, but in the absence of multivariate analysis, univariate analysis was accepted. If HRs were not presented, they were calculated from the survival curve data as described by Tierney et al. [22].

\section{Assessment of included studies}

There are no criteria for evaluation of treatment described in prognostic cohort studies included in systematic reviews. Consequently, each study was assessed by two researchers (YY and XL) following the Newcastle-Ottawa Scale (NOS) for assessing the quality of cohort studies [23]. The maximum NOS score is 9 points, and studies with scores $>5$ points were classified as high quality. Disagreements were resolved by discussion with a third researcher (HW).

\section{Statistical analysis}

Data analysis and processing were carried out using Stata/ SE version 13.0 (StataCorp LP, College Station, TX, USA) provided by the Cochrane Collaboration. Disagreements were resolved through discussion. OS, PFS and DFS were evaluated using $\mathrm{HR}$ and $95 \% \mathrm{CI}$ to describe the size of the treatment effect. $\chi^{2}$ tests were conducted at $\alpha=0.05$, with $P<0.1$ as significant. The measure of heterogeneity was $I^{2}$, and $<25 \%$ indicated low heterogeneity, $25-50 \%$ indicated moderate heterogeneity, and $>50 \%$ indicated high heterogeneity. A fixed effects model was used for studies without heterogeneity, and a random effects model was used for studies with heterogeneity. Meanwhile, subgroup analysis and meta-regression methods were used for heterogeneity analysis. Publication bias was assessed by the Egger test using Stata/SE version 13.0, and the results are shown in funnel plots. Sensitivity analysis was conducted by the meta-trim method.

\section{Results}

Included studies and quality assessment

A total of 122 relevant studies were retrieved; 98 of which were excluded at the initial assessment of titles and abstracts, and the full-text of the remaining 24 was further screened. Nineteen eligible nonrandomized studies 


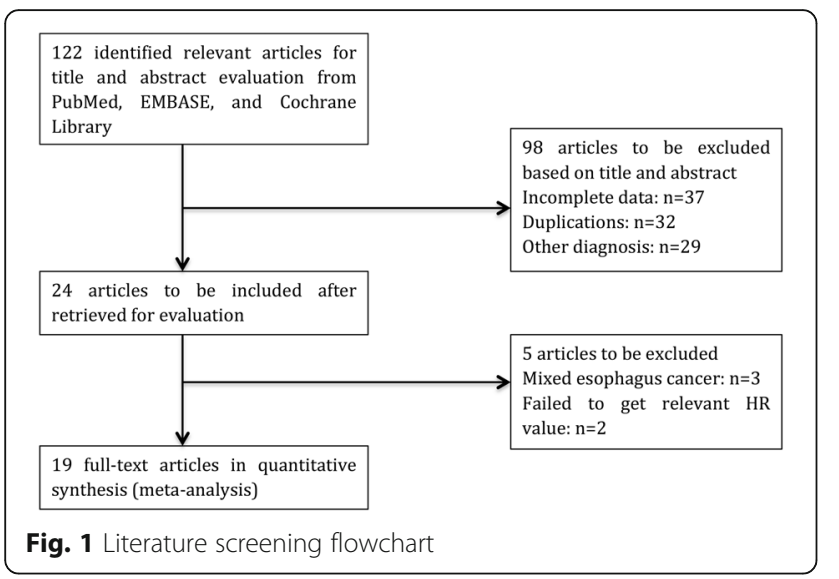

[24-42], all of which were cohort studies and included a total of 5475 patients, were included in the analysis. A flowchart of the inclusion and exclusion criteria of each study is shown in Fig. 1. Two researchers agreed on the 19 studies that were finally selected. All studies included patients with pretreatment NLR and survival data, and the study data and quality assessment results of each study are summarized in Table 1. The Cox regression hazard model used to adjust for potential confounding bias included the majority but not all of the included studies. If multivariate analysis of survival data was unavailable, univariate analysis was adopted for assessment of the survival data. The HNC tumor sites included the mouth, nasal and paranasal sinuses, nasopharynx, larynx and hypopharynx.

\section{OS of HNC patients and subgroup analysis by NLR cutoff value}

Fourteen studies were included in the meta-analysis of OS. The mortality risk of patients with high NLR was 1.84 times that of patients with low NLR. The difference was significant $(\mathrm{HR}=1.84,95 \% \mathrm{CI}: 1.53-2.23 ; P<0.001$; heterogeneity, $I^{2}=37.2 \%, P=0.074$; Fig. 2a). Subgroup analysis by NLR cutoff value revealed a higher mortality risk in patients with high NLR compared to those with low NLR. The difference reached significance $(2.1<$ cutoff $<3, \mathrm{HR}=1.71,95 \% \mathrm{CI}: 1.34-2.17, P<0.001$; heterogeneity, $I^{2}=47.6 \%, P=0.064 ; 3 \leq$ cutoff $<4, \mathrm{HR}=1.94,95 \%$ CI: 1.235-3.064, $P=0.005$; heterogeneity, $I^{2}=18.3 \%, P=0.294$; cutoff $\geq 4, \mathrm{HR}=2.414,95 \%$ CI: $1.696-3.436, P<0.001$, heterogeneity: $I^{2}=0.0 \%, P=0.675$; Fig. $\left.2 \mathrm{~b}\right)$. In the subgroup-

Table 1 Characteristics and quality assessment results for each included publications

\begin{tabular}{|c|c|c|c|c|c|c|c|c|c|c|}
\hline Study & Country & Ethnicity & Tumors & Patients(female/male) & Age(range) & Result & $\begin{array}{l}\text { Follow-up } \\
\text { (month) }\end{array}$ & Uni\Multi & $\begin{array}{l}\text { Cutoff } \\
\text { value }\end{array}$ & $\begin{array}{l}\text { NOS } \\
\text { Score }\end{array}$ \\
\hline Sun et al, 2016 [24] & China & Asian & $\mathrm{NC}$ & $251(71 \backslash 180)$ & $46(15-76)$ & OS PFS & $50(5-84)$ & Multi & 2.6 & 8 \\
\hline Wong et al, 2015 [25] & UK & Caucasian & LSCC & $140(19 \backslash 121)$ & $66(36-92)$ & OS DFS & $41(2-103)$ & Multi & 3.1 & 8 \\
\hline Fu et al, 2016 [26] & China & Asian & LSCC & $420(7 \backslash 413)$ & $60(33-84)$ & OS CSS & ungiven & Multi & 2.59 & 7 \\
\hline An et al, 2011 [27] & China & Asian & $\mathrm{NC}$ & $363(89 \backslash 274)$ & $47(12-76)$ & DSS MFS & $62(2-92)$ & Multi & 3.73 & 7 \\
\hline Li et al, 2015 [28] & China & Asian & NC & $363(89 \backslash 274)$ & $47(12-76)$ & DSS & $14.7(3.22-92.9)$ & Multi & 2.81 & 8 \\
\hline He et al, 2012 [29] & China & Asian & $\mathrm{NC}$ & $1410(383 \backslash 1027)$ & $46.1(13-79)$ & OS PFS & $41(2-60)$ & Multi & 2.74 & 7 \\
\hline Fang et al, 2013 [30] & China & Asian & OCscC & $226(19 \backslash 207)$ & $52.47(27.0-84.0)$ & OS DFS & ungiven & Uni & 2.44 & 6 \\
\hline Nakahira et al, 2016 [31] & Japan & Asian & NS & $100(14 \backslash 86)$ & $65.2(37-85)$ & CSS & $37.85(4-92)$ & Multi & 3 & 8 \\
\hline Perisanidis et al, 2013 [32] & Austria & Caucasian & OCsCC & $97(30 \backslash 67)$ & ungiven & DSS & $\begin{array}{l}>5 \text { years or } \\
\text { until death }\end{array}$ & Multi & 1.9 & 7 \\
\hline Charles et al, 2016 [33] & Australia & Caucasian & HNSCC & $145(30 \backslash 115)$ & $63(23-86)$ & OS RFS & $29(1.5-84)$ & Multi & 5 & 8 \\
\hline Tu et al, 2015 [34] & China & Asian & LSCC & $141(4 \backslash 137)$ & $59(36-87)$ & OS DFS & $51(5-102)$ & Multi & 2.17 & 7 \\
\hline Moon et al, 2016 [35] & Korea & Asian & HNSCC & $153(24 \backslash 129)$ & $57(16-78)$ & $\begin{array}{l}\text { OS PFS } \\
\text { CSS }\end{array}$ & $39.5(4.7-62.6)$ & Multi & 3.3 & 8 \\
\hline Rachidi et al, 2016 [36] & America & Caucasian & HNSCC & $543(123 \backslash 420)$ & 58.8 & OS & $64.4(2-156)$ & Multi & 4.39 & 8 \\
\hline Song et al, 2015 [37] & China & Asian & HSCC & $146(10 \backslash 136)$ & $57.5(34-89)$ & OS & $33.2(2-128)$ & Uni & 2.3 & 7 \\
\hline Salim et al, 2015 [38] & Turkey & Caucasian & HNSCC & 79 (8\71) & $59(28-85)$ & OS & ungiven & Uni & 2.93 & 6 \\
\hline Haddad et al, 2015 [39] & Australia & Caucasian & $\mathrm{HNC}$ & $46(8 \backslash 38)$ & $59(43-81)$ & $\begin{array}{l}\text { OS MFS } \\
\text { RFS }\end{array}$ & $34(13-47)$ & Uni & 5 & 5 \\
\hline Rassouli et al, 2015 [40] & Canada & Caucasian & HNSCC & $273(75 \backslash 198)$ & $64+\ldots 12$ & DFS & $45(42-48)$ & Uni & 4.27 & 6 \\
\hline Selzer et al, 2015 [41] & Austria & Caucasian & $\mathrm{HNC}$ & $318(121 \backslash 247)$ & ungiven & OS & ungiven & Uni & 1.58 & 7 \\
\hline Kim et al, 2016 [42] & Korea & Asian & $\mathrm{HNC}$ & 104 (9\95) & $58(20-82)$ & OS PFS & $39(4.8-82.5)$ & Multi & 3 & 8 \\
\hline
\end{tabular}

NC nasopharyngeal carcinoma, LSCC laryngeal squamous cell carcinoma, OCSCC Oral Cavity Squamous Cell Carcinoma, HNSCC Head and neck squamous cell carcinoma, HSCC hypopharyngeal squamous cell carcinoma, HNC head and neck cancer, Uni univariate analysis, MFS metastasis-free survival, Multi multivariate analysis, NOS score Newcastle-Ottawa Scale score, $>5$ meant relative good quality 


\begin{tabular}{|c|c|c|c|}
\hline \multicolumn{2}{|l|}{$\begin{array}{l}\text { OS } \\
\text { Author (Year) }\end{array}$} & $\mathrm{HR}(95 \% \mathrm{Cl})$ & $\begin{array}{l}\% \\
\text { Weight }\end{array}$ \\
\hline \multicolumn{4}{|l|}{ OS for $2.1<$ cutoff $<3$} \\
\hline Sun W (2016) & $\longrightarrow$ & $1.87(0.89,3.94)$ & 4.91 \\
\hline FuY (2016) & +1 & $1.30(0.99,1.70)$ & 14.95 \\
\hline He JR (2012) & $\rightarrow$ & $1.57(1.04,2.38)$ & 10.47 \\
\hline Fang $\mathrm{HY}$ (2013) & $\rightarrow$ & $2.04(1.04,4.02)$ & 5.67 \\
\hline Tu XP (2015) & $\rightarrow$ & $2.18(1.21,3.92)$ & 6.91 \\
\hline Song $Y(2015)$ & $\rightarrow$ & $2.99(1.91,4.68)$ & 9.70 \\
\hline Salim DK (2015) & +1 & $1.03(0.55,1.94)$ & 6.26 \\
\hline Selzer E (2015) & $\rightarrow$ & $1.58(1.01,2.48)$ & 9.60 \\
\hline Subtotal (I-squared $=47.6 \%, p=0.064)$ & 0 & $1.71(1.34,2.17)$ & 68.44 \\
\hline \multicolumn{4}{|l|}{ OS for $3 \leq$ cutoff $<4$} \\
\hline Wong BY (2015) & ? & $2.01(0.71,5.67)$ & 2.85 \\
\hline Moon H (2016) & $\stackrel{1}{1}$ & $3.22(1.44,7.22)$ & 4.32 \\
\hline Kim DY (2016) & + & $1.52(0.93,2.48)$ & 8.75 \\
\hline Subtotal (I-squared $=18.3 \%, p=0.294)$ & $\diamond$ & $1.95(1.24,3.06)$ & 15.92 \\
\hline \multicolumn{4}{|l|}{ OS for cutoff $\geq 4$} \\
\hline Charles KA (2016) & $\longrightarrow$ & $3.64(1.34,9.88)$ & 3.04 \\
\hline Rachidi S (2016) & $\rightarrow$ & $2.30(1.56,3.40)$ & 11.18 \\
\hline Haddad CR (2015) & & $1.95(0.42,8.96)$ & 1.42 \\
\hline Subtotal $(1-$ squared $=0.0 \%, p=0.675)$ & 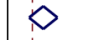 & $2.41(1.70,3.44)$ & 15.63 \\
\hline Overall (I-squared $=37.2 \%, p=0.079)$ & $\diamond$ & $1.84(1.53,2.23)$ & 100.00 \\
\hline \multicolumn{4}{|c|}{ NOTE: Weights are from random effects analysis } \\
\hline .01 & 5 & & \\
\hline \multicolumn{4}{|c|}{$\begin{array}{l}\text { Fig. } 2 \text { Forest plots of studies evaluating HRs of the NLR on OS and } \\
\text { subgroup based on cutoff value }\end{array}$} \\
\hline
\end{tabular}

analysis of ethnicity, either Asian [24, 26, 29, 30, 34, 35, 37, 42] or Caucasian [25, 33, 36, 38, 39, 41] patients with an evaluated indicated NLR a poor predictor of overall survival. All the results above are shown in Table 2.

\section{PFS and DFS for HNC patients}

The meta-analysis of PFS showed that malignancy was more likely to progress in patients with high NLR than in those with low NLR. The difference was significant (HR $=2.17$, 95\% CI: $1.20-3.92 ; P<0.001$; Fig. 3a). Patients with high NLR had shorter DFS than those with low NLR. The difference reached significance $(\mathrm{HR}=2.18,95 \% \mathrm{CI}$ : 1.46-3.24; $P<0.001$; Fig. 3b).

\section{RFS and MFS for HNC patients}

The meta-analysis of RFS showed that the probability of tumor recurrence after treatment was greater in patients with high NLR than in those with low NLR. The difference was significant $(\mathrm{HR}=1.63,95 \% \mathrm{CI}$ : 1.09-2.45; $P=0.017$; heterogeneity, $I^{2}=68.7 \%, P=0.022$; Fig. 4a). There were three studies [27, 28, 39] that analyzed the correlation between the MFS and NLR. Patients with an elevated NLR had a higher probability of distant metastasis after treatment compared with those with a low NLR, the HR was 1.92 (95\% CI: 1.36-2.72; $P<0.001$; Fig. 4b). There was no statistically significant heterogeneity $\left(I^{2}=0.0 \% ; P=0.614\right)$.

\section{Publication bias and sensitivity analysis}

In the sensitivity analysis, the trim and fill method was used to combine six sets of data. The corrected data were consistent with the original results $(\mathrm{HR}=1.459$, 95\% CI: $1.174-1.813 ; P=0.001)$, indicating stable funnel plots of the meta-analysis (Fig. 5a). Publication bias was tested by the Egger test $(P=0.135)$, which indicated the absence of publication bias for OS (Fig. 5b).

\section{Discussion}

This study was the first to evaluate the association of NLR in peripheral blood and prognosis in HNC patients. We found that patients with elevated pretreatment NLRs had predictable decreases in OS, DSS and PFS. Also, with increasing NLR cutoff value, mortality risk had a corresponding increasing trend, and patients were increasingly prone to local recurrence and distant metastasis. Our meta-analysis was consistent with previous studies of other malignant tumors. Other meta-analyses revealed better prognosis in patients with colorectal, non-small cell lung, stomach and prostate cancer who had low pretreatment NLR compared to those who had high NLR [15-19]. Pretreatment NLR reflects the status of systemic inflammation and the immune system.

Table 2 Summary of meta-analysis results

\begin{tabular}{|c|c|c|c|c|c|c|c|c|c|}
\hline \multirow[t]{2}{*}{ Outcomes } & \multirow[t]{2}{*}{ Variable } & \multirow[t]{2}{*}{$\mathrm{N}$} & \multirow[t]{2}{*}{ References } & \multicolumn{2}{|c|}{ Fixed-effect model } & \multicolumn{2}{|c|}{ Random-reffect model } & \multicolumn{2}{|c|}{ Heterogeneity } \\
\hline & & & & $\mathrm{HR}(95 \% \mathrm{Cl})$ & $\mathrm{p}$ & $\mathrm{HR}(95 \% \mathrm{Cl})$ & $\mathrm{p}$ & 12 & $\mathrm{p}$ \\
\hline \multirow[t]{7}{*}{ OS } & Ethnicity & & & & & & & & \\
\hline & Asian & 8 & {$[24,26,29,30,34,35,37,42]$} & $1.72(1.46,2.03)$ & $<0.001$ & $1.87(1.46,2.40)$ & $<0.001$ & $49 \%$ & 0.056 \\
\hline & Caucasian & 6 & {$[25,33,36,38,39,41]$} & $1.85(1.44,2.37)$ & $<0.001$ & $1.83(1.34,2.51)$ & $<0.001$ & $26 \%$ & 0.239 \\
\hline & cutoff value & & & & & & & & \\
\hline & $2.1<$ cutoff $<3$ & 8 & {$[24,26,29,30,34,37,38,41]$} & $1.63(1.39,1.91)$ & $<0.001$ & $1.71(1.43,2.17)$ & $<0.001$ & $47.60 \%$ & 0.064 \\
\hline & $3<=$ cutoff $<4$ & 3 & {$[25,35,42]$} & $1.88(1.28,2.77)$ & 0.001 & $1.95(1.24,3.06)$ & 0.04 & $18.30 \%$ & 0.249 \\
\hline & cutoff $>=4$ & 3 & {$[33,36,39]$} & $2.41(1.70,3.44)$ & $<0.001$ & $2.41(1.70,3.44)$ & $<0.001$ & 0 & 0.675 \\
\hline DFS & & 4 & {$[25,30,34,40]$} & $1.99(1.46,2.71)$ & $<0.001$ & $1.99(1.46,2.71)$ & $<0.001$ & 0 & 0.457 \\
\hline MFS & & 3 & {$[27,28,39]$} & $1.92(1.36,2.72)$ & $<0.001$ & $1.92(1.36,2.72)$ & $<0.001$ & 0 & 0.614 \\
\hline PFS & & 5 & {$[24,29,35,38,42]$} & $1.60(1.37,1.87)$ & $<0.001$ & $2.17(1.20,3.92)$ & 0.01 & $91.30 \%$ & 0 \\
\hline
\end{tabular}




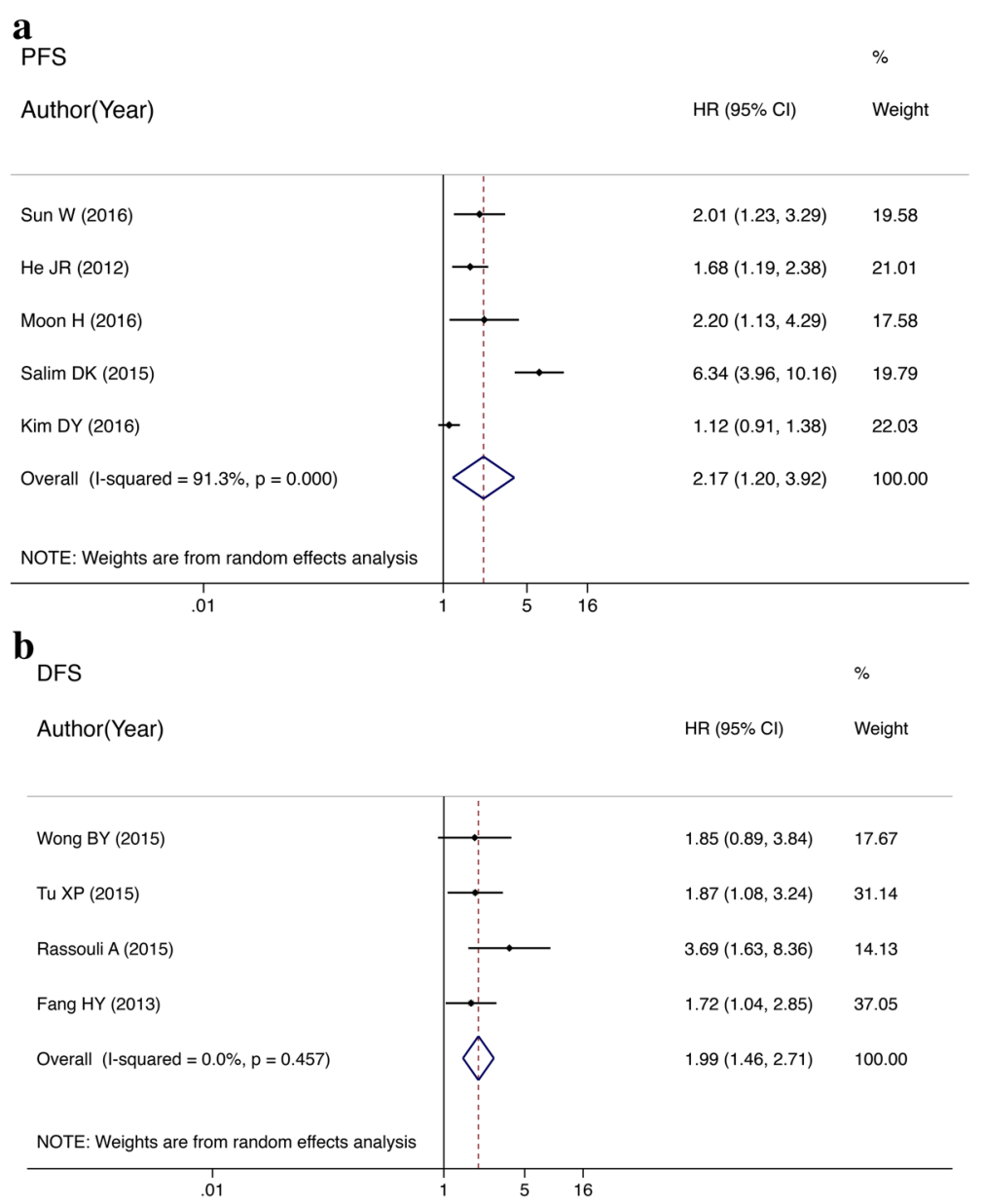

Fig. 3 a Forest plots of studies evaluating HRs of the NLR on PFS for head and neck cancer. $\mathbf{b}$ Forest plots of studies evaluating HRs of the NLR on DFS for head and neck cancer

However, the cause of poor prognosis in HNC patients with elevated NLR requires further investigation.

Elevation of neutrophils reflects systemic as well as local inflammatory responses. Neutrophils provide a microenvironment conducive to the growth of tumor cells, and they promote tumor progression and invasion of malignant tumor cells [43]. Neutrophils produce and secrete tumor-promoting growth factors, such as epidermal growth factor, vascular endothelial growth factor, interleukin (IL)-6 and IL-8, that can promote tumor cell activation and facilitate tumor development, invasion and metastasis $[8,9]$. In addition to producing cytokines, neutrophils secrete proteases, such as specific matrix metalloproteinases $[44,45]$, cysteine cathepsins $[46,47]$ and serine proteases [48]. These proteases can disrupt the connections between cells and degrade extracellular matrix and basement membrane proteins, thereby facilitating the migration of tumor cells [46-49]. They also promote epithelial cell proliferation, activate dormant tumor cells, and trigger revascularization [50], forming a link between inflammation and cancer. An increase in the number of neutrophils surrounding cancerous tissue can suppress antitumor immune responses while activating $\mathrm{T}$ lymphocytes and natural killer (NK) cells [51]. Thus, elevation of neutrophils and release of associated cytokines play a role in tumor metastasis and indicate poor prognosis in patients with malignant tumors.

In contrast, a reduction in the number of lymphocytes reflects decreased activity of lymphokine-activated killer cells [52], with inhibition of the monitoring of the host immune response [53]. The reduction of lymphocytes includes cells of the innate immune system, such as B lymphocytes, NK cells, CD4 $4^{+}$helper $\mathrm{T}$ lymphocytes and $\mathrm{CD}^{+}$cytotoxic $\mathrm{T}$ lymphocytes, leading to suppression of the immune response [7,54]. Additionally, reduction of the number of lymphocytes results in decreased release of cytokines, such as interferon and tumor necrosis factor- $\alpha$ by tumor macrophages. These cytokines promote apoptosis of tumor cells, which is a key host defense against tumor cell invasion. The collective effect of these changes is attenuation of the antitumorspecific immune system $[55,56]$. There is also a link 


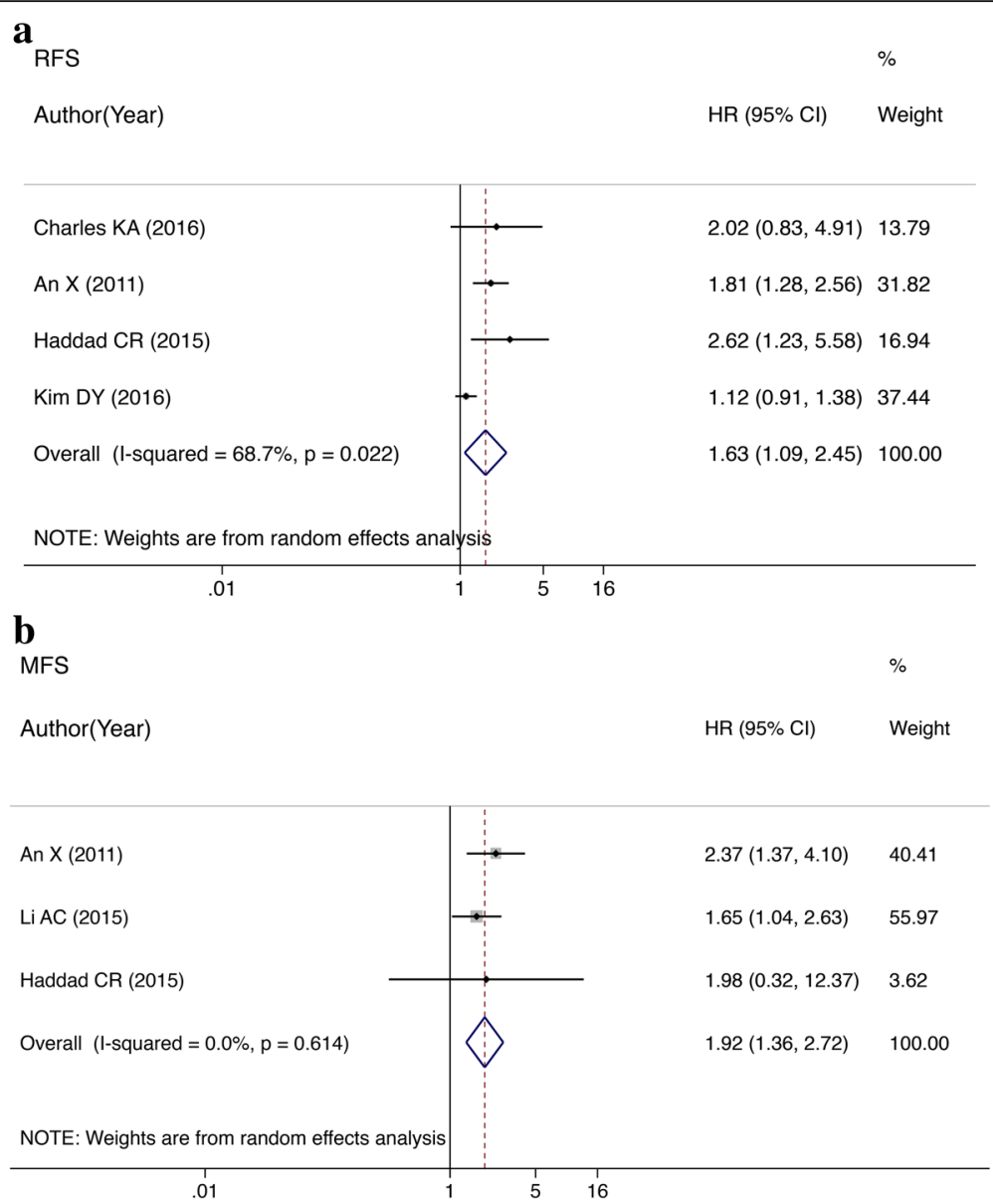

Fig. 4 a Forest plots of studies evaluating HRs of the NLR on RFS for head and neck cancer. b Forest plots of studies evaluating HRs of NLR on MFS for head and neck cancer

between the immune system and systemic inflammation. Wong et al. [25] proposed that chronic inflammation is associated with increased myeloid-derived suppressor cells (MDSCs), which suppress the immune response. They also found that MDSC-mediated immune suppression resulted in dysfunction of the acquired ( $\mathrm{T}$ cells) and innate (NK cells) immune systems; both of which play a major role in scavenging pathogens and mutant cells under normal conditions.

This study demonstrated that pretreatment NLR can be used to evaluate prognosis in HNC patients, but the optimum NLR cutoff value remains unclear. In the studies we analyzed, the NLR cutoff values ranged from 2.1 to 4.39 and were selected from the means of all patients in each study, or on the basis of previous research. Different studies used different cutoff values, making it difficult to perform the meta-analysis using a single, defined cutoff value. In order to obtain the optimal range of cutoff values, we divided the range into three equal groups for subgroup analysis using NLR cutoff values of 3.0 and 4.0, and a performed a meta-analysis of each subgroup. It is noteworthy that the increase in NLR resulted in similar mortality risks in subgroups 1 and 2, whereas the risk was significantly greater in subgroup 3 than in the other two subgroups. We infer that the prognostic value of NLR in HNC patients is influenced by a range of cutoff values. Optimally, we recommend using a continuous range of NLR values, rather than point values when selecting and comparing NLR cutoff values in future studies.

This meta-analysis had several limitations. First, all included studies were retrospective observational studies, and although multivariate analysis can control for confounding factors to a certain degree, selection bias was inevitable. Second, the NLR values could easily have been affected by infectious diseases, chronic infections, and use of glucocorticoid hormones that might have been present in the same period. Inflammation and NLR elevation are also believed to be associated with coronary heart diseases including acute coronary syndrome [57]. Interference of the NLR values by potential confounding factors associated with other diseases was thus inevitable. Third, NLR is closely associated with other variables 

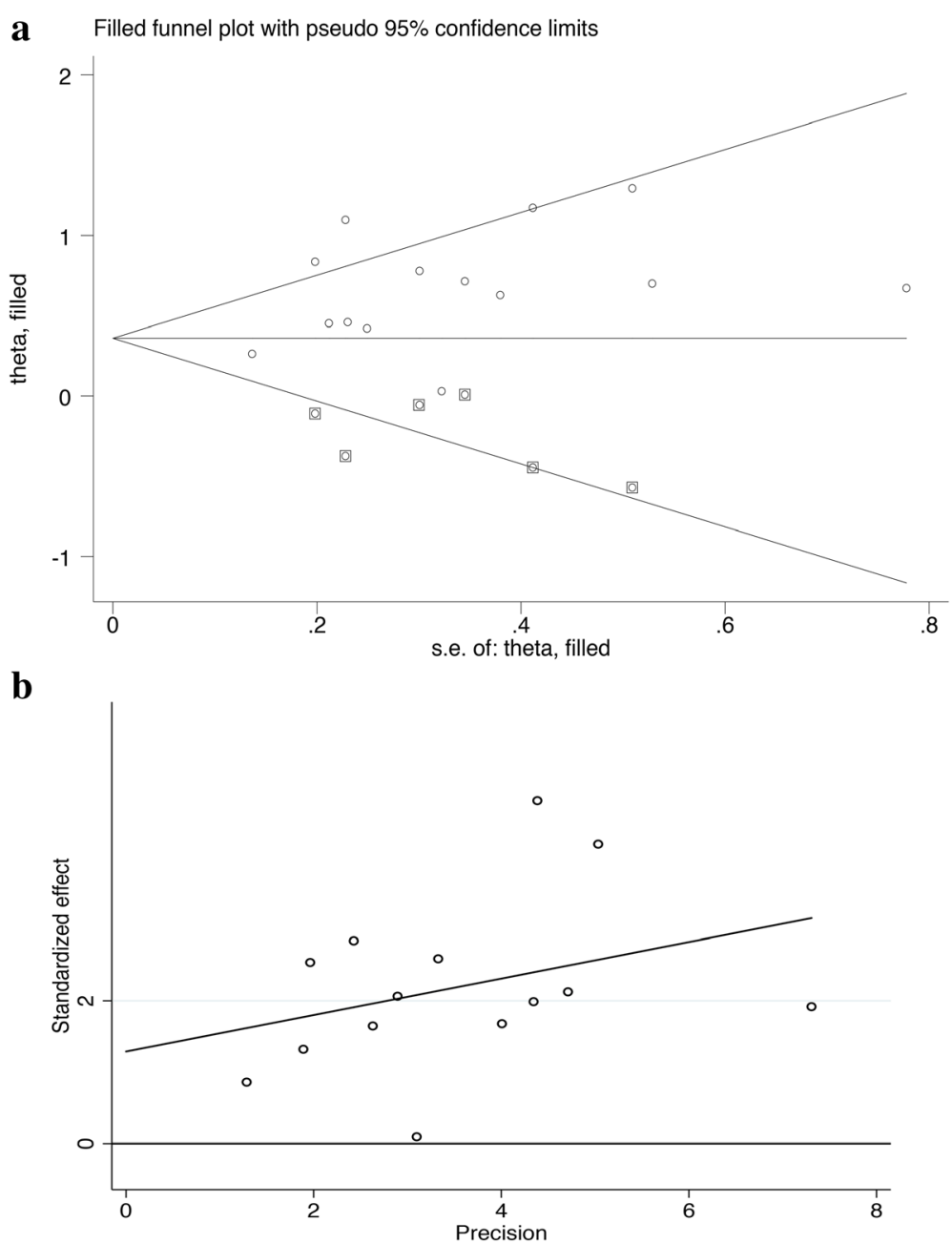

Fig. 5 a Begg's funnel plot with pseudo 95\% confidence limits. b Egger's publication bias plot

associated with systemic inflammation, such as Creactive protein and platelet-to-lymphocyte ratio. Interactions among these factors might have resulted in high collinearity in multivariate analysis by the Cox regression model, thereby influencing the evaluation of prognosis by NLR alone. Finally, there was a risk of reporting bias related to the method of retrieving full-text studies. Some studies did not report clinically significant results, and thus did not contribute to the calculated HR values, and some studies only included positive results in the data analysis.

\section{Conclusion}

This meta-analysis showed that HNC patients with elevated pretreatment NLR had poor prognosis and were prone to local invasion and distant metastasis. NLR, which is easily obtained from peripheral blood samples, can help clinicians to determine the prognosis of HNC patients. Preoperative and postoperative interventions to regulate inflammatory and immune responses have a place in the long-term treatment of $\mathrm{HNC}$, but future studies are required to validate the clinical use of NLR.

\section{Abbreviations}

Cls: Confidence intervals; DFS: Disease-free survival; DSS: Disease-specific survival; HR: Hazard ratio; IL: Interleukin; MFS: Metastasis-free survival; Multi: Multivariate analysis; NLR: Neutrophil-to-lymphocyte ratio; NOS: Newcastle-Ottawa Scale; OS: Overall survival; PFS: Progression-free survival; RFS: Recurrence-free survival

\section{Acknowledgments}

The authors thank the study participants in each of the individual studies for their involvement.

\section{Funding}

National Science Foundation of China No. 81102057 supported this work The funding body had no role in the design of the study and collection, analysis, and interpretation of data and in writing the manuscript.

\section{Availability of data and materials}

Meta-analysis is a secondary analysis, which the data are all fully available without restriction, and all the material can be found in the included original studies. 


\section{Authors' contributions}

$W L, J T L$ and $A H Y$ were responsible for conception and design of the study. YLY and XYL did the studies selection, data extraction, statistical analyses and the writing of paper. HLW and AHY participated in studies selection and data extraction and provided statistical expertise. YLY, XYL and HBW contributed to the literature search, studies selection, and figures. JTL and $W L$ reviewed and edited the manuscript extensively. All of the authors were involved in interpretation of results, read and approved the final manuscript.

\section{Ethics approval and consent to participate}

All analyses were based on previous published studies, thus no ethical approval and patient consent are required.

\section{Consent for publication}

Not applicable.

\section{Competing interests}

The authors declare that they have no competing interests.

\section{Publisher's Note}

Springer Nature remains neutral with regard to jurisdictional claims in published maps and institutional affiliations.

\section{Author details}

${ }^{1}$ Department of Otorhinolaryngology, the First Affiliated Hospital of China Medical University, Shenyang, Liaoning Province, People's Republic of China. ${ }^{2}$ Department of Radiology, Shengjing Hospital of China Medical University, Shenyang, Liaoning Province, People's Republic of China. ${ }^{3}$ Department of Clinical Epidemiology and Center of Evidence Based Medicine, the First Affiliated Hospital of China Medical University, Shenyang, Liaoning Province, People's Republic of China. ${ }^{4}$ Department of Cardiovascular Surgery \& Electro-chemotherapy, China-Japan Friendship Hospital, Beijing, People's Republic of China.

\section{Received: 13 September 2016 Accepted: 15 March 2018} Published online: 04 April 2018

\section{Reference}

1. Torre LA, Bray F, Siegel RL, Ferlay J, Lortet-Tieulent J, Jemal A. Global cancer statistics, 2012. CA Cancer J Clin. 2015;65(2):87-108.

2. Siegel RL, Miller KD, Jemal A. Cancer statistics, 2016. CA Cancer J Clin. 2016; 66(1):7-30.

3. Dasgupta S, Koch R, Westra WH, Califano JA, Ha PK, Sidransky D, Koch WM Mitochondrial DNA mutation in normal margins and tumors of recurrent head and neck squamous cell carcinoma patients. Cancer Prev Res (Phila). 2010;3(9):1205-11.

4. Argiris A, Karamouzis MV, Raben D, Ferris RL. Head and neck cancer. Lancet. 2008;371(9625):1695-709.

5. Balkwill F, Charles KA, Mantovani A. Smoldering and polarized inflammation in the initiation and promotion of malignant disease. Cancer Cell. 2005;7(3):211-7.

6. Baniyash M, Sade-Feldman M, Kanterman J. Chronic inflammation and cancer: suppressing the suppressors. Cancer Immunol Immunother. 2014; 63(1):11-20.

7. Hanahan D, Coussens LM. Accessories to the crime: functions of cells recruited to the tumor microenvironment. Cancer Cell. 2012;21(3):309-22.

8. Hanahan D, Weinberg RA. Hallmarks of cancer: the next generation. Cell. 2011;144(5):646-74.

9. Hanahan D, Weinberg RA. The hallmarks of cancer. Cell. 2000;100(1):57-70.

10. Hainaut $P$, Plymoth $A$. Targeting the hallmarks of cancer: towards a rational approach to next-generation cancer therapy. Curr Opin Oncol. 2013;25(1):50-1.

11. Kim S, Miller BJ, Stefanek ME, Miller AH. Inflammation-induced activation of the indoleamine 2,3-dioxygenase pathway: relevance to cancer-related fatigue. Cancer. 2015;121(13):2129-36.

12. Baniyash M. Myeloid-derived suppressor cells as intruders and targets: clinical implications in cancer therapy. Cancer Immunol Immunother. 2016; 65(7):857-67.

13. OuYang LY, Wu XJ, Ye SB, Zhang RX, Li ZL, Liao W, Pan ZZ, Zheng LM Zhang XS, Wang Z, et al. Tumor-induced myeloid-derived suppressor cells promote tumor progression through oxidative metabolism in human colorectal cancer. J Transl Med. 2015;13:47.
14. de Raaf PJ, Sleijfer S, Lamers CH, Jager A, Gratama JW, van der Rijt CC. Inflammation and fatique dimensions in advanced cancer patients and cancer survivors: an explorative study. Cancer. 2012;118(23):6005-11.

15. Malietzis G, Giacometti M, Kennedy RH, Athanasiou T, Aziz O, Jenkins JT. The emerging role of neutrophil to lymphocyte ratio in determining colorectal cancer treatment outcomes: a systematic review and meta-analysis. Ann Surg Oncol. 2014;21(12):3938-46.

16. Yin Y, Wang J, Wang $X, G u$ L, Pei H, Kuai S, Zhang Y, Shang Z. Prognostic value of the neutrophil to lymphocyte ratio in lung cancer: a meta-analysis. Clinics (Sao Paulo). 2015;70(7):524-30.

17. Sun J, Chen X, Gao P, Song Y, Huang X, Yang Y, Zhao J, Ma B, Gao X, Wang $Z$. Can the neutrophil to lymphocyte ratio be used to determine gastric Cancer treatment outcomes? A systematic review and Meta-analysis. Dis Markers. 2016;2016:7862469.

18. Kacan T, Babacan NA, Seker M, Yucel B, Bahceci A, Eren AA, Eren MF, Kilickap S. Could the neutrophil to lymphocyte ratio be a poor prognostic factor for non small cell lung cancers? Asian Pac J Cancer Prev. 2014;15(5):2089-94.

19. Templeton AJ, Pezaro C, Omlin A, McNamara MG, Leibowitz-Amit R, VeraBadillo FE, Attard G, de Bono JS, Tannock IF, Amir E. Simple prognostic score for metastatic castration-resistant prostate cancer with incorporation of neutrophil-to-lymphocyte ratio. Cancer. 2014:120(21):3346-52.

20. Moher D, Liberati A, Tetzlaff J, Altman DG, Group P. Preferred reporting items for systematic reviews and meta-analyses: the PRISMA statement. BMJ. 2009;339:b2535.

21. Higgins JP, Green S Cochrane Handbook for Systematic Reviews of Interventions. Available at http://handbook.cochrane.org/. Accessed 05 Jan 2013.

22. Tierney JF, Stewart LA, Ghersi D, Burdett S, Sydes MR. Practical methods for incorporating summary time-to-event data into meta-analysis. Trials. 2007;8:16.

23. Wells GA, Shea B, O'Connell D, et al. The Newcastle-Ottawa scale (NOS) for assessing the quality of nonrandomised studies in meta- analyses. 2008. http://www.ohri.ca/programs/clinical_epidemiology/oxford.asp

24. Sun W, Zhang L, Luo M, Hu G, Mei Q, Liu D, Long G, Hu G. Pretreatment hematologic markers as prognostic factors in patients with nasopharyngeal carcinoma: neutrophil-lymphocyte ratio and platelet-lymphocyte ratio. Head Neck. 2016;38(Suppl 1):E1332-40

25. Wong BY, Stafford ND, Green VL, Greenman J. Prognostic value of the neutrophil-to-lymphocyte ratio in patients with laryngeal squamous cell carcinoma. Head Neck. 2016:38(Suppl 1):E1903-8.

26. Fu Y, Liu W, OuYang D, Yang A, Zhang Q. Preoperative neutrophil-toymphocyte ratio predicts long-term survival in patients undergoing Total laryngectomy with advanced laryngeal squamous cell carcinoma: a singlecenter retrospective study. Medicine (Baltimore). 2016;95(6):e2689.

27. An X, Ding PR, Wang FH, Jiang WQ, Li YH. Elevated neutrophil to lymphocyte ratio predicts poor prognosis in nasopharyngeal carcinoma. Tumour Biol. 2011;32(2):317-24.

28. Li AC, Xiao WW, Wang L, Shen GZ, Xu AA, Cao YQ, Huang SM, Lin CG, Han $F$, Deng XW, et al. Risk factors and prediction-score model for distant metastasis in nasopharyngeal carcinoma treated with intensity-modulated radiotherapy. Tumour Biol. 2015:36(11):8349-57.

29. He JR, Shen GP, Ren ZF, Qin H, Cui C, Zhang Y, Zeng YX, Jia WH. Pretreatment levels of peripheral neutrophils and lymphocytes as independent prognostic factors in patients with nasopharyngeal carcinoma. Head Neck. 2012:34(12):1769-76.

30. Fang HY, Huang XY, Chien HT, Chang JT, Liao CT, Huang JJ, Wei FC, Wang $\mathrm{HM}$, Chen $\mathrm{IH}$, Kang $\mathrm{CJ}$, et al. Refining the role of preoperative C-reactive protein by neutrophil/lymphocyte ratio in oral cavity squamous cell carcinoma. Laryngoscope. 2013;123(11):2690-9.

31. Nakahira M, Sugasawa M, Matsumura S, Kuba K, Ohba S, Hayashi T, Minami K, Ebihara Y, Kogashiwa Y. Prognostic role of the combination of platelet count and neutrophil-lymphocyte ratio in patients with hypopharyngeal squamous cell carcinoma. Eur Arch Otorh inolaryngol. 2016;273(11):3863-7.

32. Perisanidis C, Kornek G, Poschl PW, Holzinger D, Pirklbauer K, Schopper C, Ewers R. High neutrophil-to-lymphocyte ratio is an independent marker of poor disease-specific survival in patients with oral cancer. Med Oncol. 2013; 30(1):334.

33. Charles KA, Harris BD, Haddad CR, Clarke SJ, Guminski A, Stevens M, Dodds T, Gill AJ, Back M, Veivers D, et al. Systemic inflammation is an independent predictive marker of clinical outcomes in mucosal squamous cell carcinoma of the head and neck in oropharyngeal and non-oropharyngeal patients. BMC Cancer. 2016;16(1):124. 
34. Tu XP, Qiu QH, Chen LS, Luo XN, Lu ZM, Zhang SY, Chen SH. Preoperative neutrophil-to-lymphocyte ratio is an independent prognostic marker in patients with laryngeal squamous cell carcinoma. BMC Cancer. 2015;15:743.

35. Moon H, Roh JL, Lee SW, Kim SB, Choi SH, Nam SY, Kim SY. Prognostic value of nutritional and hematologic markers in head and neck squamous cell carcinoma treated by chemoradiotherapy. Radiother Oncol. 2016;1 18(2):330-4.

36. Rachidi S, Wallace K, Wrangle JM, Day TA, Alberg AJ, Li Z. Neutrophil-tolymphocyte ratio and overall survival in all sites of head and neck squamous cell carcinoma. Head Neck. 2016;38(Suppl 1):E1068-74.

37. Song Y, Liu H, Gao L, Liu X, Ma L, Lu M, Gao Z. Preoperative neutrophil-tolymphocyte ratio as prognostic predictor for hypopharyngeal squamous cell carcinoma after radical resections. J Craniofac Surg. 2015;26(2):e137-40.

38. Salim DK, Mutlu H, Eryilmaz MK, Salim O, Musri FY, Tural D, Gunduz S, Coskun HS. Neutrophil to lymphocyte ratio is an independent prognostic factor in patients with recurrent or metastatic head and neck squamous cell cancer. Mol Clin Oncol. 2015;3(4):839-42.

39. Haddad CR, Guo L, Clarke S, Guminski A, Back M, Eade T. Neutrophil-tolymphocyte ratio in head and neck cancer. J Med Imaging Radiat Oncol. 2015;59(4):514-9.

40. Rassouli A, Saliba J, Castano R, Hier M, Zeitouni AG. Systemic inflammatory markers as independent prognosticators of head and neck squamous cell carcinoma. Head Neck. 2015;37(1):103-10.

41. Selzer E, Grah A, Heiduschka G, Kornek G, Thurnher D. Primary radiotherapy or postoperative radiotherapy in patients with head and neck cancer: comparative analysis of inflammation-based prognostic scoring systems. Strahlenther Onkol. 2015;191(6):486-94.

42. Kim DY, Kim IS, Park SG, Kim H, Choi YJ, Seol YM. Prognostic value of posttreatment neutrophil-lymphocyte ratio in head and neck squamous cell carcinoma treated by chemoradiotherapy . Auris Nasus Lanynx. 2017;44(2):199-204

43. Grivennikov SI, Greten FR, Karin M. Immunity, inflammation, and cancer. Cell. 2010;140(6):883-99.

44. Egeblad M, Werb Z. New functions for the matrix metalloproteinases in cancer progression. Nat Rev Cancer. 2002;2(3):161-74.

45. Lynch CC, Matrisian LM. Matrix metalloproteinases in tumor-host cell communication. Differentiation. 2002;70(9-10):561-73.

46. Gocheva V, Joyce JA. Cysteine cathepsins and the cutting edge of cancer invasion. Cell Cycle. 2007;6(1):60-4.

47. Mohamed MM, Sloane BF. Cysteine cathepsins: multifunctional enzymes in cancer. Nat Rev Cancer. 2006;6(10):764-75.

48. Laufs S, Schumacher J, Allgayer H. Urokinase-receptor (u-PAR): an essential player in multiple games of cancer: a review on its role in tumor progression, invasion, metastasis, proliferation/dormancy, clinical outcome and minimal residual disease. Cell Cycle. 2006;5(16):1760-71.

49. Joyce JA, Pollard JW. Microenvironmental regulation of metastasis. Nat Rev Cancer. 2009;9(4):239-52

50. Schwartsburd PM. Age-promoted creation of a pro-cancer microenvironment by inflammation: pathogenesis of dyscoordinated feedback control. Mech Ageing Dev. 2004;125(9):581-90.

51. Petrie HT, Klassen LW, Kay HD. Inhibition of human cytotoxic T lymphocyte activity invitro by autologous peripheral blood granulocytes. J Immunol. 1985;134(1):230-4

52. Teramukai S, Kitano T, Kishida Y, Kawahara M, Kubota K, Komuta K, Minato K, Mio T, Fujita Y, Yonei T, et al. Pretreatment neutrophil count as an independent prognostic factor in advanced non-small-cell lung cancer: an analysis of Japan multinational trial organisation LC00-03. Eur J Cancer. 2009;45(11):1950-8.

53. Schreiber RD, Old $\sqcup$, Smyth MJ. Cancer immunoediting: integrating immunity's roles in cancer suppression and promotion. Science. 2011;331(6024):1565-70.

54. Ishigami S, Natsugoe S, Tokuda K, Nakajo A, Che X, Iwashige H, Aridome K, Hokita S, Aikou T. Prognostic value of intratumoral natural killer cells in gastric carcinoma. Cancer. 2000;88(3):577-83.

55. Avci N, Deligonul A, Tolunay S, Cubukcu E, Fatih Olmez O, Altmisdortoglu O, Tanriverdi O, Aksoy A, Kurt E, Evrensel T. Prognostic impact of tumor lymphocytic infiltrates in patients with breast cancer undergoing neoadjuvant chemotherapy. J BUON. 2015;20(4):994-1000.

56. Song MK, Chung JS, Seol YM, Kim SG, Shin HJ, Choi YJ, Cho GJ, Shin DH. Influence of low absolute lymphocyte count of patients with nongerminal center type diffuse large B-cell lymphoma with R-CHOP therapy. Ann Oncol. 2010;21(1):140-4

57. Bhat T, Teli S, Rijal J, Bhat H, Raza M, Khoueiry G, Meghani M, Akhtar M, Costantino T. Neutrophil to lymphocyte ratio and cardiovascular diseases: a review. Expert Rev Cardiovasc Ther. 2013;11(1):55-9.

\section{Submit your next manuscript to BioMed Central and we will help you at every step:}

- We accept pre-submission inquiries

- Our selector tool helps you to find the most relevant journal

- We provide round the clock customer support

- Convenient online submission

- Thorough peer review

- Inclusion in PubMed and all major indexing services

- Maximum visibility for your research

Submit your manuscript at www.biomedcentral.com/submit
Biomed Central 